\title{
A review of the potential risks associated with chemicals present in poured-in-place rubber surfacing
}

\author{
Courtney Janes*, Ludmilla Rodriguez*, Chris Kelly*, Theron White*, and Chad Beegan* \\ *Healthy Physical Environments, Alberta Health Services
}

\begin{abstract}
Poured-in-place (PIP) rubber surface systems are becoming a popular material for playground and play area surfaces due to their customizability, durability, and impact protection. The material is constructed from crumb rubber, which is made from recycled tires as well as synthetic components and other additives, such as a binding agent. Several government agencies and nongovernmental organizations have commissioned studies and status reports to identify possible health risks related to exposure to the chemical hazards present in PIP surface materials. Various routes of exposure were considered such as inhalation, ingestion, and dermal contact. After a review of the available literature addressing potential chemical hazards of PIP surfaces, no health risks were noted. Some information gaps, such as limited experimental data specific to PIP surface systems, were identified at the time of the review.
\end{abstract}

Key words: playgrounds, poured-in-place, rubber surface, recycled tires, crumb rubber.

The poured-in-place (PIP) rubber surface systems have been in use in playgrounds for over 20 years. The use of PIP surfaces has become more popular worldwide within the last 10 years because the PIP industry offers different design and colour choices to make them more attractive (Dandes, 2016). According to several PIP surface manufacturers and installers, the surface system can be used for applications such as private and public playgrounds, basketball courts, tennis courts, running and walking tracks, splash pads, and swimming pool decks (Dandes, 2016; Fortco, n.d.; Robertson Recreational Surfaces, n.d.).

The material components of PIP surfaces come from crumb rubber, manufactured from recycled tires for the base layer and synthetic rubber granules, either virgin or recycled, for the topping layer (IPEMA, n.d.). The components of each layer are held together by moisture cure polyurethane (PU) binding agents and are installed on-site on top of a hard sub-base such as concrete or asphalt (Dandes, 2016; Fortco, n.d.; Robertson Recreational Surfaces, n.d.). Public concern with chemical hazards associated with crumb rubber surfaces have been raised with agencies like the US Environmental Protection Agency (EPA, 2016). To assess the potential impact of crumb rubber on users' health, several studies have been conducted by public health institutions, universities, sports federations, and manufacturers of crumb rubber surfaces (CPSC, 2016; EPA, 2016; WHO, 2010).

The focus of this review was to determine if the chemical hazards associated with materials in PIP surface systems for playgrounds present a health risk to users. Any potential physical hazards associated with the PIP surface systems, such as extreme

Corresponding author: Chad Beegan (email: chad.beegan@ahs.ca) surface temperatures or its ability to protect the user from impacts (e.g., head injuries), were not within the scope of this review.

\section{Methods}

A review of organizations providing standards and guidelines for playgrounds and play equipment was conducted. Primary sources for the review included reports and studies from governmental agencies, academic research, and nongovernmental organizations (NGOs). As current policies in North America regarding playgrounds are being informed by standards such as the Canadian Standards Association International (2014), the US Consumer Product Safety Commission (CPSC), and the ASTM playground standards (CPSC, 2015), these standards were included in the search criteria. Reputable international NGOs with a public health focus, such as the World Health Organization (WHO) were also included in the search criteria.

Specifics about the composition of the products, binding agents, and other additives as well as the installation and maintenance processes were obtained from a Google search for the websites of product manufacturers. The literature search was conducted between February and May of 2017 using Google Scholar, Alberta Health Services Knowledge Resource Service, and PubMed databases with the search terms: recycled rubber surfacing, poured-in-place rubber, playground surfacing, crumb rubber, recycled tire composition, and recycled tires. The terms were searched separately and in combination with public health risks, health risk assessment, safe, odour, and inhalation. 


\section{Results}

\section{PIP material composition}

\section{Typical material composition of a tire}

The exact composition of individual tires is not known because of corporate proprietary restrictions; the composition of recycled tire rubber, as reported by Pehlken and Essadiqi (2005), is an assumed average of all tires. As shown in Figure 1, tires are manufactured from natural and synthetic rubber along with numerous chemical additives including zinc, sulphur, carbon black (CB), synthetic amorphous silica (SAS) and oils that contain polycyclic aromatic hydrocarbons (PAHs) and volatile organic compounds (Gunturgeni, 2009; Pehlken and Essadiqi, 2005).

Because crumb rubber is manufactured from recycled tires, it contains the same chemicals as tire rubber (Pehlken and

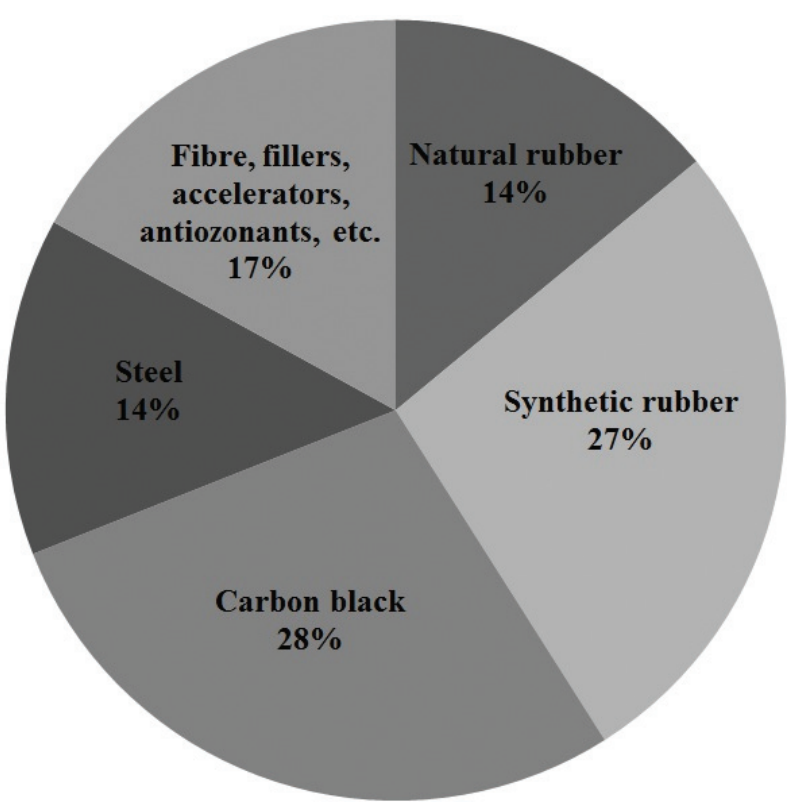

Figure 1. Typical passenger automobile tire composition in North America. Adapted from Table 2-1 by Pehlken and Essadiqi (2005).
Essadiqi, 2005). ASTM International developed standardized classification and particle size distribution schemes for crumb rubber produced from recycled tires (ASTM International, $2013,2015)$. Tires are recycled by a process of separating the steel and fabric components, shredding the rubber component, and dividing the resulting rubber particles into different sizes to produce recycled tire crumb rubber (Pehlken and Essadiqi, 2015).

\section{PIP surface construction}

PIP surface systems consist of two poured rubber layers that are installed onto a hard subsurface, generally concrete, asphalt, or compacted stone (Figure 2). The base layer exploits the properties of a synthetic rubber compound contained within the crumb rubber called styrene butadiene rubber (SBR) that, when the crumb rubber is combined with a PU binding agent, produces the impact absorbing qualities of PIP surface systems (IPEMA, n.d.). SBR is a synthetic copolymer of styrene and butadiene and has properties similar to natural rubber as well as good abrasion resistance, excellent impact strength, very good resilience, and a high tensile strength (Elbex, n.d.; Lattime, 2000). The thickness of this layer will vary based on the fall height of play space equipment (Dandes, 2016; Fortco, n.d.; Robertson Recreational Surfaces, n.d.).

The topping layer does not contain crumb rubber from recycled tires but is formed using ethylene propylene diene monomer (EPDM) or thermal plastic vulcanized (TPV) rubber granules that can be a combination of virgin and recycled material, and it is bonded together with a PU binder (Dufton, 2001; IPEMA, n.d.; OEHHA, 2007). The choice between EPDM and TPV depends largely on the type of project, the cost, and the installer's preference (Klemenc, 2014). EPDM is an organic synthetic elastomer that is resistant to weathering, ozone, UV exposure, water, heat, and compression set (Elbex, n.d.; EPA, 2010; Klemenc, 2014). TPV is a synthetic blend of a thermoplastic material that can be heated and reset into a particular shape when cooled (Bombardier, 2010). The topping layer is generally about $1.27 \mathrm{~cm}$ thick and acts as a barrier to limit direct contact of the playground users to the chemicals contained in the crumb rubber of the base layer (Dandes, 2016; Fortco, n.d.; OEHHA, 2007; Robertson Recreational Surfaces, n.d.). Information on the permeability of the topping layer in the cured form was not found during the review.

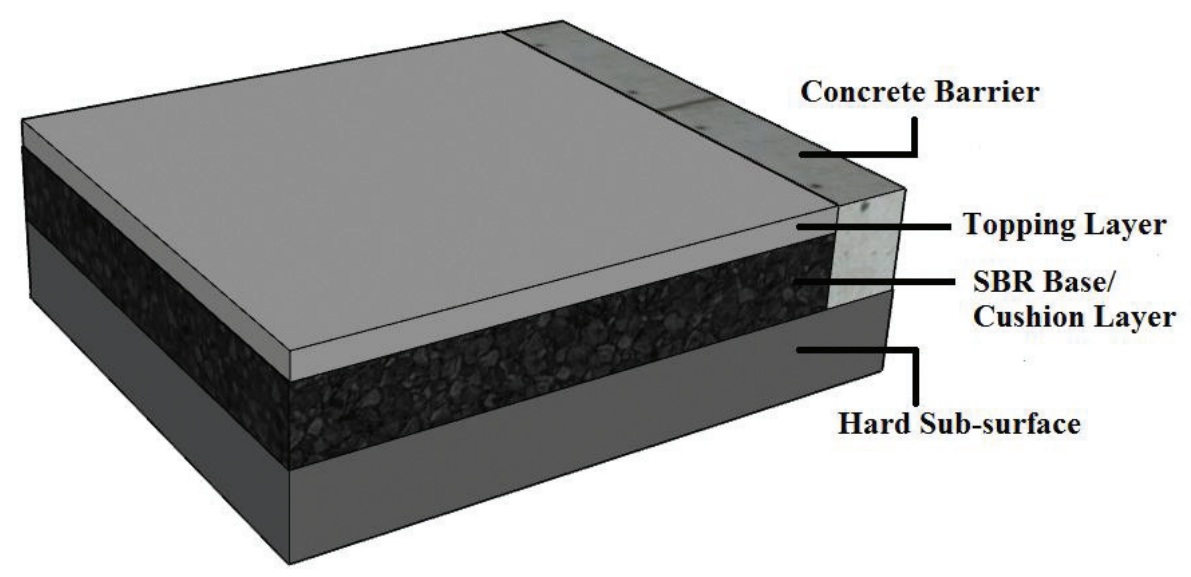

Figure 2. Poured-in-place rubber surface system construction. 
Moisture cure PU binding agents are produced by combining aromatic or aliphatic diisocyanates with polyols and other chemical additives (American Chemistry Council, n.d.; IPEMA, n.d.). Depending on the PIP application, there are two different types of binders: aromatic PU binders and aliphatic PU binders. According to several PIP surface manufacturers/installers, both types of PU products bond well to rubber particles (Robertson Recreational Surfaces, n.d.). Therefore, the decision of which binder to use may be based on cost and final surface appearance.

\section{Chemicals of concern}

\section{Polycyclic aromatic hydrocarbons}

In 2016, Environment and Climate Change Canada conducted a screening assessment of distillate aromatic extracts, which include aromatic extender oils found in the composition of tires and the resulting crumb rubber. These oils can have high levels of aromatic compounds including PAHs (Environment and Climate Change Canada, 2016). Based on a study included in the assessment that measured PAH levels of crumb rubber surfaces, Environment and Climate Change Canada (2016) reported that exposure to aromatic PAHs from these surfaces is considered to be low. The study found PAH levels from crumb rubber surfaces to be within the range of ambient air background levels (Menichini et al., 2011). The assessment also stated that Canada has adopted legislation limiting PAH content in the production of tires (Environment and Climate Change Canada, 2016). Therefore, PAHs in the crumb rubber of PIP surfaces will be further reduced in the future as older tires are phased out. In addition, PIP surfaces are in a bound state when cured and the crumb rubber base layer, where the PAHs are found, is separated from the users by the topping layer.

\section{CB and SAS}

Other chemicals of possible concern are $\mathrm{CB}$ and SAS, reinforcing fillers for synthetic rubber (Figure 1). Concerns about CB and SAS arise from their association with manmade nanomaterials and their potential risk to human health following inhalation exposure after tires are recycled into crumb rubber (ETRMA, 2012). Experiments have provided evidence for the carcinogenicity of $\mathrm{CB}$ in animal models, but there is inadequate evidence of carcinogenicity in humans (WHO, 2010). A recent study on respiratory morbidity in workers after exposure to SAS at five German production plants showed only limited indications of minor effect due to chronic exposures at the workplace (Taeger et al., 2016). In addition, the International Agency for Research on Cancer (1997) categorized SAS as a group 3 carcinogen or not classifiable as to its carcinogenicity to humans. Both SAS and CB become chemically and/or physically bound to the rubber matrix of the tire during the manufacturing process, and once the PIP rubber aggregate for the base layer is formed in its bound state they are relatively unavailable for release and unlikely to cause any adverse health effects (ETRMA, 2012).

\section{Diisocyanates}

Diisocyanates are used to produce PU binding agents and are highly reactive organic compounds containing two isocyanate groups (American Chemistry Council, n.d.). They are used primarily to make a wide range of PU products. The most commonly used diisocyanates for PIP applications are methylene diphenyl diisocyanate (MDI) and hexamethylene diisocyanate (HDI) (NIOSH, 2008). Free/unreacted diisocyanates are wellknown respiratory and skin irritants in the workplace, and the Materials Safety Data Sheet identifies required personal protective equipment to prevent worker exposure to diisocyanate in both the liquid and vapor state (Human Resources and Social Development Canada, 2007; NIOSH, 2008). Even though MDI and HDI are used in the manufacturing of many products, including PU binding agents, most of these products are cured during the application process and should have relatively low amounts of unreacted diisocyanates as they harden. Fully reacted PU polymer is considered chemically inert in the PIP surface and does not represent a risk to user health (ATSDR, 2015; EPA, 2011; Human Resources and Social Development Canada, 2007).

\section{Discussion}

In 2007, the Office of Environmental Health Hazard Assessment in California commissioned a study to assess PIP surfaces for the release of chemicals that could cause toxicity in children following ingestion or dermal contact. Three routes of child exposure to chemicals in the rubber were considered: ingestion of loose rubber tire shreds, ingestion via hand-to-surface contact followed by hand-to-mouth contact, and skin sensitization via dermal contact. Overall, there was no determined health risk from the above routes of exposure to PIP surfaces on playgrounds (OEHHA, 2007). However, a CPSC (2016) status report still recommended users always wash their hands after playing on crumb rubber surfaces to minimize potential exposures, particularly before eating. In addition, the topping layer should be maintained according to manufacturer's instructions to prevent crumb rubber in the base layer from being exposed. This can include inspecting the surface and removing loose debris every $2-3$ weeks or using patch kits and rebinders for repairs (IPEMA, n.d.).

Limited information was found in the scientific literature, specifically regarding the chemical hazards of recycled tires in PIP playground surfacing (EPA, 2016; Pehlken and Essadiqi, 2005). No epidemiological studies, health risk assessments, or comprehensive reviews related to human exposure to PIP surfaces were identified in the peer-reviewed literature during this review. To date, some research has been conducted on the health impacts related to crumb rubber use, but the majority has focused on artificial turf fields and the risks related to the ingestion of crumb rubber particles (EPA, 2016). Artificial turf is constructed from synthetic grass fibers, looped into a backing material, used to simulate natural grass on sports/playing fields. A combination of sand and loose crumb rubber is used as infill between the fibers for better performance and comfort (Flemming, 2011). Although artificial turf infill and PIP surfaces both utilize crumb rubber, the crumb rubber in PIP surfaces is in a bound state and confined in the base layer of the finished product. Therefore, the crumb rubber used in PIP surfaces is not considered to present the same level of risk as unbound crumb rubber in artificial turf fields (OEHHA, 2007). 
Another gap that has not been adequately addressed in the literature is leaching and off gassing of chemicals from the product as it ages and wears. Information on how the lifespan of PIP surfaces is determined and if there is an increase risk to chemical hazards as the product ages was limited at the time of this review. The authors of an EPA status report on crumb rubber for play areas concluded that additional studies are needed to support the safety of recycled tire crumb rubber use in PIP surfacing (EPA, 2016).

\section{Conclusion}

Overall, the literature search did not identify any health risks associated with the crumb rubber or other additives of PIP surface systems when in its bound state and confined beneath the topping layer. Chemical hazards were identified for individual components of the material, but not the product as a whole. Ingredients, such as $\mathrm{SAS}$ and $\mathrm{CB}$ are expected to be inextricably bound in the product and under normal conditions of use are not expected to present a health risk from inhalation or other routes of exposure (WHO, 2010). In addition, the chemicals used to produce the PU binding agents are considered inert once the product has cured and are a minimal health risk to users.

Further research is needed to determine if the risk of chemical hazards increases over the lifespan of the product. This can provide information about an appropriate operational lifespan for the product, ensuring the risk to public health remains low. In addition, if inspection of playgrounds is within the scope of the local public health authority, monitoring the overall condition and maintenance of PIP surfaces should be considered part of the inspection to prevent public exposure to the crumb rubber base layer. Proper PIP surface maintenance by the owner/operator (as per manufacturer's instructions) should also be encouraged by the public health authority so that worn or damaged areas in the topping layer are appropriately repaired.

\section{Acknowledgements}

The authors would like to sincerely thank Angela Eykelbosh, an Environmental Health and Knowledge Translation Scientist with the National Collaborating Centre for Environmental Health (NCCEH), for the information and input she provided. Contributions from both the Healthy Physical Environments team of Safe Healthy Environments and the Environmental Public Health playground subcommittee within Alberta Health Services were appreciated. The authors would also like to acknowledge Shaun McCabe, Manager of Occupational Health \& Safety Alberta Region at Liberty Tire Recycling Canada; Danielle Young, Alberta Environmental Rubber Products; and Davina McIntyre, Softline Solutions, for their insight in regard to product manufacturing and installation.

A full list of websites and organizations searched for this article can be made available from the authors upon request.

\section{References}

Agency for Toxic Substances and Disease Registry (ATSDR). 2015. Toluene diisocyanate and methylendiphenyl diisocyanate ToxFAQs. Available at: www.atsdr.cdc.gov/toxfaqs/tfacts206.pdf.
American Chemistry Council. n.d. Aliphatic diisocyanates. Available at: adi.americanchemistry.com/Aliphatic-Diisocyanates.

ASTM International. 2013. Standard test methods for rubber compounding materials - Determination of particle size distribution of recycled vulcanizate particulate rubber (D5644-01). West Conshohocken, PA: ASTM International.

ASTM International. 2015. Standard classification for rubber compounding materials - Recycled vulcanizate particulate rubber (D5603-01). West Conshohocken, PA: ASTM International.

Bombardier. 2010. Marking of plastics, rubbers and thermoplastic elastomers. Available at: www.bombardier.com/content/dam/ Websites/bombardiercom/supporting-documents/BT/ Bombardier-Transportation-Marking-of-Plastics-Rubbers-andThermoplastic-Elastomers-Standard-Doc-ID-number-000018-en. pdf.

Canadian Standards Association International (CSA). 2014. Children's playspaces and equipment (CAN/CSA Z614-14). Toronto, ON: CSA Group.

Consumer Product Safety Commission (CPSC). 2015. Handbook for public playground safety (Publication \#325). Washington, DC: U.S. Government Printing Office.

Consumer Product Safety Commission (CPSC). 2016. Status report on tire crumb rubber full questions and answers. Available at: www. cpsc.gov/content/status-report-on-tire-crumb-rubber-fullquestions-and-answers.

Dandes, R. 2016. Scratching below the surface: How safe is your playground surface? Recreation Management. Available at: recmanagement.com/feature/201610FE04/1.

Dufton, P.W. 2001. End-of-life tyres: Exploiting their value. Shrewsbury, UK: Smithers Rapra Publishing.

Elbex. n.d. General properties of elastomers. Available at: www. elbex-us.com/sites/default/files/General\%20Properties\%20of\%20 Elastomers.pdf.

Environment and Climate Change Canada. 2016. Draft screening assessment petroleum sector stream approach: Stream 4-Distillate aromatic extracts. Ottawa, ON: Government of Canada.

Environmental Protection Agency (EPA). 2010. S. crap tires: Handbook on recycling applications and management for the U.S. and Mexico (EPA530-R-10-010). Cincinnati, OH: National Service Center for Environmental Publications.

Environmental Protection Agency (EPA). 2011. Methylene diphenyl diisocyanate (MDI) and related compounds action plan (RIN 2070-ZA15). Washington, DC: U.S. Government Printing Office.

Environmental Protection Agency (EPA). 2016. Federal research action plan on recycled tire crumb used on playing fields and playgrounds: Status report (EPA/600/R-16/364). Washington, DC: U.S. Government Printing Office.

European Tyre and Rubber Manufacturer's Association (ETRMA). 2012. Reinforcing fillers in the rubber industry-assessment as potential nanomaterials with a focus on tyres. Available at: www.etrma. org/uploads/Modules/Documentsmanager/201201-etrma-factsheet---carbon-black-and-silica-2.pdf.

Flemming, P. 2011. Artificial turf systems for sport surfaces: Current knowledge and research needs. Proc. Inst. Mech. Eng. P J. Sports Eng. Technol. 225(2): 43-63. doi: 10.1177/1754337111401688

Fortco. n.d. Architectural specification: Playgrounds (poured-inplace). Available at: www.fortco.ca/pdf/specification_playgrounds_ EPDM.pdf. 
Gunturgeni, S. 2009. Polymers and plastics: An introduction, green life generations. Available at: ajigunturgeni.blogspot.ca/2009/12/ polymers-and-plastics-introduction.html.

Human Resources and Social Development Canada. 2007. Control measures guide-Control measures to eliminate or reduce exposure of employees to isocyanates in spray-painting operations (LT-18107-07). Ottawa, ON: Government of Canada.

International Agency for Research on Cancer (IARC). 1997. Silica, some silicates, coal dust and para-aramid fibrils. IARC Monographs on the Evaluation of Carcinogenic Risks to Humans. IARC Working Group on the Evaluation of Carcinogenic Risk to Humans, International Agency for Research on Cancer, Lyon, France. Vol. 68. pp. 41-242.

International Play Equipment Manufacturers Association (IPEMA). n.d. Frequently asked questions about various types of playground surfaces. Available at: ipema.wpengine.com/wp-content/ uploads/2017/06/IPEMA-FAQ-Surfacing.pdf.

Klemenc, S.E. 2014. Rubber safety surfacing: Offers color, comfort and security. Concrete Décor. 14(3). Available at: www.concretedecor.net/decorativeconcretearticles/vol-14-no-3-april-2014/rubbersafety-surfacing/

Lattime, R. 2000. Styrene-butadiene rubber. Kirk-Othmer encyclopedia of chemical technology. Wiley, Hoboken, NJ. doi: 10.1002/047 1238961.1920251812012020.a01

Menichini, E., Abate, V., Deluca, S., di Domenico, A., Fochi, I., Forte, G, Iacovella, N., Iamiceli, A.L., and Izzo, P. 2011. Artificial-turf playing fields: Contents of metals, PAHs, PCBs, PCDDs, and PCDFs, inhalation exposure to PAHs and related preliminary risk assessment. Sci. Total Environ. 409: 4950-4957. doi: 10.1016/j.scitotenv. 2011.07.042

National Institute for Occupational Safety and Health (NIOSH). 2008. Isocyanates. Available at: www.cdc.gov/niosh/topics/ isocyanates.

Office of Environmental Health Hazard Assessment (OEHHA). 2007. Evaluation of health effects of recycled waste tires in playground and track products. Sacramento, CA: Integrated Waste Management Board.

Pehlken, A. and Essadiqi, E. 2005. Scrap tire recycling in Canada-A reference for all parties involved in the tire recycling industry on the options available for end-of-life of off-the-road (OTR) and passenger tires from an economic and environmental perspective (MTL 2005-08(CF)). Hamilton, ON: Natural Resources Canada-CanmetMaterials.

Robertson Recreational Surfaces. n.d. Tot turf standard EPDM poured in place rubber surfacing. Available at: www.totturf.com/products/ pour-in-place/aromatic/.

Taeger, D., McCunney, R., Bailer, U., Barthel, K., Küpper, U., Brüning, T., Morfeld, P., and Merget, R. 2016 Cross-sectional study on nonmalignant respiratory morbidity due to exposure to synthetic amorphous silica. J. Occup. Environ. Med. 58(4): 376-384. doi: 10.1097/jom. 0000000000000666

World Health Organization (WHO). 2010. IARC monographs on the evaluation of carcinogenic risks to humans. Carbon Black, Titanium Dioxide, and Talc. Vol. 93: (ISBN 978928321293 5). Lyon, France: International Agency for Research on Cancer. 